\title{
Nudging in The Digital Big Data Era
}

\author{
Julia M. Puaschunder \\ The New School, Department of Economics, \\ Schwartz Center for Economic Policy Analysis \\ Columbia University, Graduate School of Arts and Sciences, \\ 116th Street Broadway, New York, USA
}

Doi: 10.19044/elp.v4no4a2 URL:http://dx.doi.org/10.19044/elp.v4no4a2

\begin{abstract}
In the current Behavioral Economics entrance into public policy science, completely undescribed remains that the implicit hidden persuasion opens a gate to deception and is an unprecedented social class division means. Today's social media revolution opens gates to a class dividing nudgital society, in which the provider of social communication tools can reap surplus value from the information shared of social media users. The social media provider thereby becomes a capitalist-industrialist, who benefits from the information shared by social media users as the consumer-worker share private information in their wish to interact with friends and communicate to public. The social media capitalist-industrialist reaps surplus value from the social media consumer-workers' information sharing, which stems from nudging social media users. For one, social media space can be sold to marketers who can constantly penetrate the consumer-worker in a subliminal way with advertisements. But also nudging occurs as the big data compiled about the social media consumer-worker can be resold to marketers and technocrats to draw inferences about consumer choices, contemporary market trends or individual personality cues used for governance control, such as, for instance, border protection and tax compliance purposes. Addressing the nudgital society allows to better understand the laws of motion of governance in the digital age, leading to the potentially unequal accumulation and concentration of power. Technological improvement in the age of information has increased the possibilities to control the innocent social media users and reap the benefits of their existence in hidden persuasion. Nudging can be criticized to be used by the ruling class to exploit the governed populace. In modern democracies, the right to rule was recently proven to be plundered in democratic votes through misguiding information of alternative facts and fake news circulated on social media. The socio-ethical crises that are rooted in the contradictory class division of the nudgital society are presented in this paper
\end{abstract}


for the first time and from there on demand for further description and research on capitalism and democracy in the digital age.

Keywords: Behavioral Economics, Behavioral Political Economy, Democratisation of information, Education, Exchange value, Governance, Libertarian Paternalism, Nudging, Nudgital, right to delete, right to be forgotten, Social media, Social media capitalist-industrialist, Social media consumer-worker, Social media slavery, Surplus Value, Use value, Winking, Winkital.

\section{Introduction}

Since the end of the 1970ies a wide range of psychological, economic and sociological laboratory and field experiments proved human beings deviating from rational choices and standard neo-classical profit maximization axioms to fail to explain how human actually behave (Kahneman \& Thaler, 1991). Human beings were shown to use heuristics in the day-to-day decision making as mental short cuts that enable to cope with information overload in a complex world (Kahneman \& Tversky, 1979; Thaler \& Sunstein, 2008).

From there on, the emerging field of behavioral insights targeted at using human heuristics and biases to improve decision making in different domains ranging from health, wealth and prosperity (Thaler \& Sunstein, 2008). Behavioral economists proposed to nudge and wink citizens to make better choices for them with many different applications. Behavioral Insights teams have been formed to advise individual governments around the globe for instance, Australia, Canada, Colombia, Germany, Italy, the United Kingdom, and the United States (World Development Report, 2015). But also intergovernmental entities such as the European Commission, or global governance institutions, such as the World Bank and the International Monetary Fund, have started using nudges and winks to improve society (World Development Report, 2015).

While the motivation behind nudging appears as a noble endeavor to foster peoples' lives around the world in very many different applications (Marglin, 1974), the nudging approach raises questions of social hierarchy and class division. The motivating force of the nudgital society may open a gate of exploitation of the populace and - based on privacy infringements stripping them involuntarily from their own decision power in the shadow of legally-permitted libertarian paternalism and under the cloak of the noble goal of welfare-improving global governance. Nudging enables nudgers to plunder the simple uneducated citizen, who is neither aware of the nudging strategies nor able to oversee the tactics used by the nudgers. The nudgers are thereby legally protected by democratically assigned positions they hold or by outsourcing strategies used, in which social media plays a crucial rule. 
In the digital age, social media revolutionized human communication around the globe, yet also opened opportunities to unprecedentedly reap benefits from information sharing and big data generation. To this day completely undescribed remains that the implicit hidden persuasion opens a gate to deception and is an unprecedented social class division means. Social media forces are captures as unfolding a class dividing nudgital society, in which the provider of social communication tools can reap surplus value from the information shared of social media users.

The social media provider thereby becomes a capitalist-industrialist, who benefits from the information shared by social media users, or so-called consumer-workers, who share private information in their wish to interact with friends and communicate to public. The social media capitalist-industrialist reaps surplus value from the social media consumer-workers' information sharing, which stems from nudging social media users. For one, social media space can be sold to marketers who can constantly penetrate the consumerworker in a subliminal way with advertisements. But also nudging occurs as the big data compiled about the social media consumer-worker can be resold to marketers and technocrats to draw inferences about consumer choices, contemporary market trends or individual personality cues used for governance control, such as, for instance, border protection and tax compliance purposes. Unprecedented computational power and storage opportunities have created the possibility to hoard information over time and put it in context with the rest of the population in order to draw inferences about the information sharer (The New York Times, November 14, 2017). ${ }^{37}$ The subjective additive utility of information shared tranche by tranche may underestimate the big data holder's advantage to reap benefits from information shared. Problems of the contemporary nudgital society (Puaschunder, 2017) are that big data compilers can reap a surplus value from selling compiled information (The New York Times, November 14, 2017) ${ }^{38}$ or manipulate vulnerable population segments based on their previously shared information (The Economist, November 4, 2017). ${ }^{39}$

The law of motion of the nudging societies holds an unequal concentration of power of those who have access to compiled data and who

37 https://www.nytimes.com/2017/11/14/business/dealbook/taxing-companies-for-usingour-personaldata.

html?rref=collection $\% 2$ Fsectioncollection $\% 2$ Fbusiness\&action=click\&contentCollection=b usiness\&reg

ion=stream \& module=stream_unit $\&$ version=latest $\&$ contentPlacement $=8 \&$ pgtype $=$ sectionfro nt

38 https://www.nytimes.com/2017/11/14/business/dealbook/taxing-companies-for-usingour-personaldata.

39 https://www.economist.com/news/leaders/21730871-facebook-google-and-twitter-weresupposed-savepolitics- 
abuse their position under the cloak of hidden persuasion and in the shadow of paternalism. In the nudgital society, information, education and differing social classes determine who the nudgers and who the nudged are. Humans end in different silos or bubbles that differ in who has power and control and who is deceived and being ruled. The owners of the means of governance are able to reap a surplus value in a hidden persuasion, protected by the legal vacuum to curb libertarian paternalism, in the moral shadow of the unnoticeable guidance and under the cloak of the presumption that some know what is more rational than others (Camerer, Issacharoff, Loewenstein, O’Donoghue \& Rabin, 2003).

All these features lead to an unprecedented contemporary class struggle between the nudgers (those who nudge) and the nudged (those who are nudged), who are divided by the implicit means of governance in the digital scenery. In this light, governing our common welfare through deceptive means and outsourced governance on social media appears critical. In combination with the underlying assumption of the nudgers knowing better what is right, just and fair within society, the digital age and social media tools hold potential unprecedented ethical challenges.

Outlining the connection of nudging and social class structure is targeted at deriving conclusions about implicit societal impetus of nudging and winking in the $21^{\text {st }}$ century. Alongside of providing an overview of behavioral sciences with an application in the public domain; a critical approach in the economic analysis of contemporary public governance through nudging and winking enabled through social media should be considered. Drawing from some of the historical foundations of political economy will aid to advance the field of behavioral economics through a critical stance on behavioral sciences and new media use for guiding on public concerns in the digital age (Heilbroner, 1988, 1999).

By revealing the contradictions of the social media age of the nudgital society, light is shed on the implicit class struggle rooted in the nudgital social relations of production. Pointing out the limitations of behavioral insights to inform about public choices accurately will be the basis of the critique of a certain ruling class nudging a wide populace by the help of social media. An analysis of the process of the circulation of information leads to conclusions about the metamorphosis of big data and their circuit. By shedding light on the inherent class division in those who nudge (the nudgers) and those who are being nudged (the nudged), the piece proposes further analysis strategies to unravel how the use of behavioral economics for the greater societal good in combination with the rise of social media big data creation may hold unknown socio-ethical downfalls. Taking a heterodox economics stance will aid with interdisciplinary improvement recommendations how to more inclusively alleviate public sector concerns in the digital age. Challenging 
contemporary behavioral insights theory is aimed at moving together towards a more inclusive future wiser, more self-informed and protected digital society.

To draw attention to this implicit struggle within society is important for various reasons: Addressing the nudgital society allows to better understand the laws of motion of governance in the digital age, leading to the potentially unequal accumulation and concentration of power. Technological improvement in the age of information has increased the possibilities to control the innocent social media users and reap the benefits of their existence in hidden persuasion.

In the age of populism, nudging can be criticized to be used by the ruling class to exploit the governed populace. In modern democracies, the right to rule was recently plundered in democratic votes through misguiding information of alternative facts and fake news circulated on social media. The socio-ethical crises that are rooted in the contradictory class division of the nudgital society are presented hereby for the first time and from there on demand for further description and research on capitalism and democracy in the digital age. This piece therefore advocates for a democratisation of information, education about nudges and well-informed distribution of transparent governance control.

* Financial support of the Eugene Lang College of The New School, Fritz Thyssen Foundation, the Janeway Center Fellowship, New School for Social Research, Prize Fellowship, the Science and Technology Global Consortium, the University of Vienna, and Vernon Arts and Sciences is gratefully acknowledged. The author thanks the students of the New School Eugene Lang College Spring 2017 'Behavioral Economics' class for most excellent feedback on the presented ideas and/or earlier versions of this paper. All omissions, errors and misunderstandings in this piece are solely the author's.

\section{References:}

Camerer, C., Issacharoff, S., Loewenstein, G., O’Donoghue, T. \& Rabin, M. (2003). Regulation for conservatives: Behavioral economics and the case for „Asymmetric Paternalism“. University of Pennsylvania Law Review, 151, 3, 1211-1254.

Heilbroner, R. (1988). Behind the veil of economics: Essays in the worldly philosophy. New York: Norton.

Heilbroner, R. (1999). The worldly philosopher. Chapter 8: The savage society of Thorstein Veblen. New York: Simon \& Schuster.

Horberg, E. J., Oveis, C., \& Keltner, D. (2011). Emotions as moral amplifiers: An appraisal tendency approach to the influences of distinct emotions upon moral judgments. Emotion Review, 3, 237-244. 
Kahneman, D. \& Tversky, A. (1979). Prospect theory: An analysis of decision under risk. Econometrica, 47, 2, 263-291.

Kahneman, D. \& Thaler, R. (1991). Economic analysis and the psychology of utility: Applications to compensation policy. American Economic Review, 81, 341-346.

Marglin, S. (1974). What do bosses do? The origins and functions of hierarchy in capitalist production. Review of Radical Political Economics, 6, 60-112.

Thaler, R. H. \& Sunstein, C. R. (2008). Nudge. Improving decisions about health, wealth, and happiness. New Haven: Yale University Press.

World Development Report (2015). Mind, society and behavior. Chapter 1

Overview: Human decision making and development policy. 